\title{
Museus no Brasil: análise socioeconômica de perfis
}

\author{
Museos en Brasil: análisis socioeconómico de perfiles
}

Brazilian Museums: a socio-economic analysis

\author{
Ana Flávia Machado \\ Nayara Souza \\ Larissa Machado'
}

Palavras chave:

Museus

Tipologia

Clusters

Brasil

\section{Resumo:}

Este trabalho tem por objetivo construir uma tipologia de museus, utilizando como fonte básica o Cadastro Nacional de Museus (CNM) do IBRAM aplicado à estatística multivariada de formação clusters. Tipologias são nada mais do que classificações que, em um conjunto heterogêneo, desenham tipos de maior uniformidade e, com isso, contribuem para reconhecimento e formulação de políticas públicas. Neste estudo, para além da distribuição espacial, incluímos variáveis socioeconômicas referentes aos municípios onde se localizam os museus, como também características referentes a esses equipamentos. São identificados seis perfis de museus no Brasil, observando-se que a concentração em determinadas unidades da federação, tamanho de município e tipo de gestão tendem a ser as variáveis mais relevantes para descrição desses tipos. 


\begin{abstract}
Resumen:
Este trabajo tiene como objetivo construir una tipología de museos, utilizando como fuente básica El Cadastro Nacional de Museus (CNM) del IBRAM aplicado a la estadística multivariada de formación clusters. Tipologías son nada más que clasificaciones que, en un conjunto heterogéneo, dibujan tipos de mayor uniformidad e, así, contibuyen para el reconocimiento e para la formulación de políticas públicas. En este estudio, además de la distribuición espacial, incluímos variables socioeconómicas referentes a las ciudades dónde se localizan los museos, como también caracteristicas referentes a estos equipamientos. Son identificados seis tipos de perfiles de museos en Brasil, observándose que la concentración en determinadas unidades de la federación, tamaño de ciudad e tipo de gestión tienden a ser las variables más relevantes para descripción de estes tipos.
\end{abstract}

\section{Palabras clave:}

Museos

Tipología

Clusters

Brasil

\section{Keywords:}

Museums

Typology

Clustering

Brazil

\section{Abstract:}

Applying Cadastro Nacional de Museus (CNM) from IBRAM as main source for a multivariate analysis of clustering, this article aims at assemble museums typology. Typologies are classifications which draw more uniformed types in heterogeneous groups, leading to recognize and formulate public politics. In addition to the space distribution, we included socio-economic variables of municipalities where the museums are located and characteristics from this equipment in this study. It is possible to identify six types of museums in Brazil, considering that concentration in some states of Brazil, city or municipality size and management tend to be the main elements to describe these classes. 


\section{Museus no Brasil: análise socioeconômica de perfis}

\section{1 - Introdução}

Entre os economistas, Jevons (18351882) foi o primeiro a reconhecer a cultura como um bem público. Neste contexto, ressaltou a importância do Estado no financiamento de museus, especialmente os de temática científica. Recentemente, Frey e Meier (2006) trataram do termo "economia de museus", enfocando dois aspectos. O primeiro se refere ao de unidade econômica, entendido como uma firma que produz serviços. Entre os vários insumos, acervo e pessoal são os mais importantes. As receitas, por outro lado, advêm do número de visitantes, compras em lojas situadas no seu interior e de marcas geradas. $O$ outro aspecto, também, enfatizado pelos autores, é a possibilidade deste equipamento ser argumento em uma função de escolha sujeita à restrição institucional e ambiental.

A concepção acima reportada pretende entender o papel de um museu em uma perspectiva teórica microeconômica, denominada teoria da escolha. Entretanto, os museus assumem papel relevante em atividades de lazer e constituem atrações turísticas importantes, podendo promover efeitos positivos de transbordamento sobre a economia local, especialmente em áreas de turismo popular (FREY; MEIER, 2006).

CWI (1980) ressalta, especialmente, este último efeito dos museus sobre a economia, pois destaca a geração de efeitos econômicos diretos e indiretos, tais como mudança da imagem da cidade; implementação de políticas públicas de segurança para criação de ambiente seguro; atração de novos investimentos e estímulo à integração, desenvolvendo identidade local e senso de pertencimento. Bille e Schulze (2008) apontam que arte e cultura podem ter um papel proe- minente para o desenvolvimento regional e urbano e, ainda mais amplo, se a definição de desenvolvimento envolver não somente geração de renda e postos de trabalho, como também melhoria da qualidade de vida da população e inclusão sociocultural. E ainda, de acordo com o IBRAM (2014), utilizando o trabalho de Rausell (2011), todos esses impactos dos museus na economia podem ser classificados em: efeitos diretos, efeitos indiretos, efeitos induzidos e efeitos externos.

Entretanto, a localização das atividades culturais, principalmente equipamentos como museus, não tem atendido a essas prerrogativas. No Brasil, Pasternak e Bógus (2012) procuraram analisar a distribuição espacial dos mesmosna cidade de São Paulo e sua relação com a população a partir de suas características sócioocupacionais. Para tal, o tecido urbano foi dividido em cinco anéis central, interior, exterior, intermediário e periférico - que são diferenciados pelas distintas características de renda, escolaridade, perfil etário e taxa de crescimento. Constatam que, em São Paulo, assim como em outras cidades brasileiras, a distribuição de equipamentos culturais segue uma trajetória histórica de concentração espacial, nas áreas centrais das grandes cidades. A maior parte desses espaços culturaisestá localizada no chamado centro expandido, isto é, nas áreas centrais e nos bairros nobres da cidade.

Considerando essa problemática, pretende-se, com esse trabalho, definir uma tipologia de museus tendo-se por fonte básica o Cadastro Nacional de Museus (CNM) do IBRAM (Instituto Brasileiro de Museus) . A definição de tipos é feita pela aplicação de análise estatística multivariada de formação clusters ao banco de dados organizado. Tipologias são nada mais do que classificações que, em um conjunto heterogêneo, desenham tipos de maior uniformidade e, com isso, contribuem para reconhecimento e formulação de políticas públicas atinentes a essas especificidades. No contexto deste estudo, para além da distribuição espacial, incluímos variáveis socioe- 
conômicas referentes aos municípios onde se localizam os museus como também características referentes a esses equipamentos.

Desse modo, o presente artigo está dividido em quatro seções, incluindo esta. $\mathrm{Na}$ segunda, tratamos da metodologia de classificação. Em seguida, apresentamos os principais resultados e, por fim, tecemos algumas considerações.

\section{2 - Construção da tipologia museal: mé- todo de agrupamentos e fontes de dados}

A análise de agrupamentos, também conhecida como cluster, é um método estatístico que nos permite agrupar elementos de uma amostra em grupos homogêneos, ou seja, elementos com características similares entre si são classificados em um mesmo grupo, que por sua vez são heterogêneos em relação aos outros diferentes grupos.

A técnica utilizada para a obtenção dos clusters foi o k-Means, um método não hierárquico. Basicamente, cada elemento amostral é alocado àquele cluster cujo ÿreqüênci (vetor de médias amostral) é o mais próximo do vetor de valores observados para o respectivo elemento (MINGOTI, 2007). Para iniciar o processo de partição é necessário escolher k centroides iniciais. Então, depois de algumas tentativas, optamos por $\mathrm{k}=6$, seis clusters.

Cada elemento da base de dados é comparado com cada reqüênci, através de uma medida da distância ao reqüênci, a distância Euclidiana. O elemento é, então, alocado no grupo cuja distância é menor. A cada novo cluster formado, novos valores dos reqüência são definidos para cada um deles. Esse processo é repetido até que não seja necessária nenhuma realocação de elementos, ou seja, todos os elementos da amostra estejam "bem alocados".

Assim, o agrupamento dos museus brasileiros em grupos homogêneos permite criar ti- pologias, buscando facilitar o entendimento da distribuição dessas instituições pelo país, por meio da combinação de características e condições socioeconômicas dos municípios.

Para tal intento, foi necessário reunir informações de varias fontes de dados. A mais importante é o Cadastro Nacional de Museus (CNM), uma plataforma on-line construída a partir de questionários próprios e coordenada pelo IBRAM que, desde 2006, mapeou mais de 3200 instituições museológicas em todo o país. Dados como localização dos museus, natureza administrativa, cobrança ou não de entrada, se há visitas guiadas, necessidade de agendamento de visitas, infraestrutura para turistas estrangeiros, existência de biblioteca e/ou arquivo histórico, se o público em geral tem acesso a essas instalações e o tipo de acervo foram incorporados. Entretanto, para esse estudo, só foram incluídos museus em funcionamento e físicos, museus esses que totalizaram 3063 unidades. Os dados são do período de março de 2006 a junho de 2015.

O Censo Demográfico de 2010, realizado pelo IBGE, reúne indicadores de todos os 5.565 municípios do Brasil. Dentre esses indicadores, extraímos para esse estudo a população dos municípios em 2010; a taxa de ensino médio de adultos com 25 anos ou mais e a proporção de domicílios com acesso a esgotamento sanitário. Essas variáveis pretendem descrever a dimensão do público, tanto pelo tamanho como também por condições associadas à escolaridade (diretamente) e à econômica (indiretamente), pois a visitação a museus, assim como a frequência a atividades culturais, está fortemente associada a essas condições (SANZ; HERRERO, 2006; BEDATE; HERRERO; SANZ, 2009; FARIA; MACHADO 2015).

O Atlas do Desenvolvimento $\mathrm{Hu}-$ mano no Brasil 2013 é uma plataforma de consulta ao Índice de Desenvolvimento Humano Municipal - IDHM - de 5.565 municípios brasileiros e ainda apresenta outros 180 indicadores. Selecionamos a 
renda média dos ocupados com ou mais de 18 anos para o estudo, em consonância com os achados na literatura sobre o tema já reportado em parágrafo anterior.

Outra fonte de dados utilizada foi o Finbra, o relatório das informações sobre despesas e receitas de cada município brasileiro, divulgadas pela Secretaria do Tesouro Nacional. As informações disponíveis são obtidas mediante a coleta dos dados contábeis por meio do Sistema de Coleta de Dados Contábeis (SISTN), em parceria com a Caixa Econômica Federal. Os dados são atualizados anualmente. Como o Finbra disponibiliza informações sobre os gastos municipais em cultura, em 2010, essa despesa foi ponderada pela população residente em cada município. A inclusão dessa informação para construção da tipologia pretende evidenciar a possível relação entre a presença destes equipamentos e a maior disponibilidade e/ou foco da administração municipal ao incentivo de atividades culturais.
Dados sobre segurança pública foram extraídos do website Datasus, departamento de informática do Sistema Único de Saúde. Trata-se de um órgão da Secretaria de Gestão Estratégica e Participativa do Ministério da Saúde com a responsabilidade de coletar, processar e disseminar informações sobre saúde. Dessa forma, incluímos informações sobre a mortalidademunícipio, óbitos por causas externas por local de ocorrência. A inclusão desteindicador se deve ao fato de se constituir em uma Proxy para descrever a violência urbana - grandes centros, onde a desigualdade de renda é mais elevada e, ademais, um empecilho à reqüência de atividades culturais que se fazem em maior extensão nos finais de semana e em horários noturnos. (DINIZ; MACHADO, 2011).

No Quadro 1 as variáveis são sumariadas, explicando o conceito e a fonte de onde as informações foram extraídas.

\section{Quadro 1 - Variáveis selecionadas}

\begin{tabular}{|c|c|c|}
\hline Variáveis & Descrição & Fonte \\
\hline Natureza administrativa & Perfil jurídico do museu & $\begin{array}{l}\text { Cadastro Nacional de } \\
\text { Museus - } 2015\end{array}$ \\
\hline Ingresso & Cobrança ou não de ingressos & $\begin{array}{l}\text { Cadastro Nacional de } \\
\text { Museus - } 2015\end{array}$ \\
\hline Tipo de acervo & $\begin{array}{l}\text { Tipologia das coleções que são } \\
\text { preservadas pelo museu }\end{array}$ & $\begin{array}{l}\text { Cadastro Nacional de } \\
\text { Museus - } 2015\end{array}$ \\
\hline Agendamento & $\begin{array}{c}\text { Necessidade de agendamento de } \\
\text { visitas }\end{array}$ & $\begin{array}{l}\text { Cadastro Nacional de } \\
\text { Museus - } 2015\end{array}$ \\
\hline Estrutura para turistas & $\begin{array}{c}\text { Infraestrutura para recebimento } \\
\text { de turista estrangeiro }\end{array}$ & $\begin{array}{l}\text { Cadastro Nacional de } \\
\text { Museus - } 2015\end{array}$ \\
\hline Visita guiada & Possibilidade de visitas guiadas & $\begin{array}{l}\text { Cadastro Nacional de } \\
\text { Museus - } 2015\end{array}$ \\
\hline Biblioteca & $\begin{array}{c}\text { Existência de biblioteca no } \\
\text { equipamento }\end{array}$ & $\begin{array}{l}\text { Cadastro Nacional de } \\
\text { Museus - } 2015\end{array}$ \\
\hline
\end{tabular}




\begin{tabular}{|c|c|c|}
\hline Acesso à biblioteca & $\begin{array}{l}\text { Acesso à biblioteca do } \\
\text { equipamento ao público }\end{array}$ & $\begin{array}{l}\text { Cadastro Nacional de } \\
\text { Museus - } 2015\end{array}$ \\
\hline Arquivo & $\begin{array}{c}\text { Existência de arquivo histórico no } \\
\text { equipamento }\end{array}$ & $\begin{array}{l}\text { Cadastro Nacional de } \\
\text { Museus - } 2015\end{array}$ \\
\hline Acesso ao arquivo & $\begin{array}{c}\text { Acesso ao arquivo histórico do } \\
\text { equipamento ao publico }\end{array}$ & $\begin{array}{l}\text { Cadastro Nacional de } \\
\text { Museus - } 2015\end{array}$ \\
\hline População em 2010 & População do município em 2010 & $\begin{array}{l}\text { Censo Demográfico } \\
\qquad \text { (IBGE) }-2010\end{array}$ \\
\hline $\begin{array}{l}\text { Proporção da população } \\
\text { com ensino médio } \\
\text { completo }(\%)\end{array}$ & $\begin{array}{l}\text { Adultos que concluíram o ensino } \\
\text { médio - } 25 \text { anos ou mais (\%) }\end{array}$ & $\begin{array}{l}\text { Censo Demográfico } \\
\qquad \text { (IBGE) }-2010\end{array}$ \\
\hline Mortalidade & $\begin{array}{l}\text { Óbitos por causas externas (por } \\
\text { ocorrência) }\end{array}$ & $\begin{array}{l}\text { Datasus - sistema único } \\
\text { de saúde }-2013\end{array}$ \\
\hline $\begin{array}{l}\text { Proporção de domicílios } \\
\text { com acesso a } \\
\text { esgotamento sanitário }\end{array}$ & $\begin{array}{c}\text { Domicílios particulares } \\
\text { permanentes com banheiro ligado } \\
\text { à rede de esgoto em geral }(\%)\end{array}$ & $\begin{array}{l}\text { Censo Demográfico } \\
\qquad \text { (IBGE) }-2010\end{array}$ \\
\hline $\begin{array}{c}\text { Despesa em cultura per } \\
\text { capita }\end{array}$ & $\begin{array}{c}\text { Total de gastos em cultura - per } \\
\text { capita }\end{array}$ & Finbra \\
\hline $\begin{array}{l}\text { Rendimento médio dos } \\
\text { ocupados }\end{array}$ & $\begin{array}{l}\text { Média dos rendimentos de todos } \\
\text { os trabalhos das pessoas } \\
\text { ocupadas de } 18 \text { anos ou mais de } \\
\text { idade. }\end{array}$ & $\begin{array}{c}\text { Atlas do } \\
\text { Desenvolvimento } \\
\text { Humano no Brasil - } 2013\end{array}$ \\
\hline
\end{tabular}

Fonte: elaboração própria

\section{3 - Tipologia museal: análise dos aglomerados}

Ao se aplicar o método de agrupamentos às variáveis selecionadas, classificamos em seis perfis tipos, clusters ou aglomerados, os 3063 museus brasileirosfísicos em funcionamento. De todas as variáveis utilizadas apenas a cobrança (ou não) de "ingresso" e a necessidade (ou não) de agenda- mento de visitas não foram relevantes para a construção dos agrupamentos, uma vez que a variabilidade dessas variáveis era ínfima, dado que a maioria dos museus brasileiros é de franca entrada e também não há necessidade de agendamento prévio para visitação. Os tipos de maior concentração de museus, conforme reportado no Gráfico 1, são o 5 com $26 \%$ da amostra, seguido pelo 1 , com $20 \%$. 


\section{Gráfico 1- Distribuição dos museus por clusters (\%)}

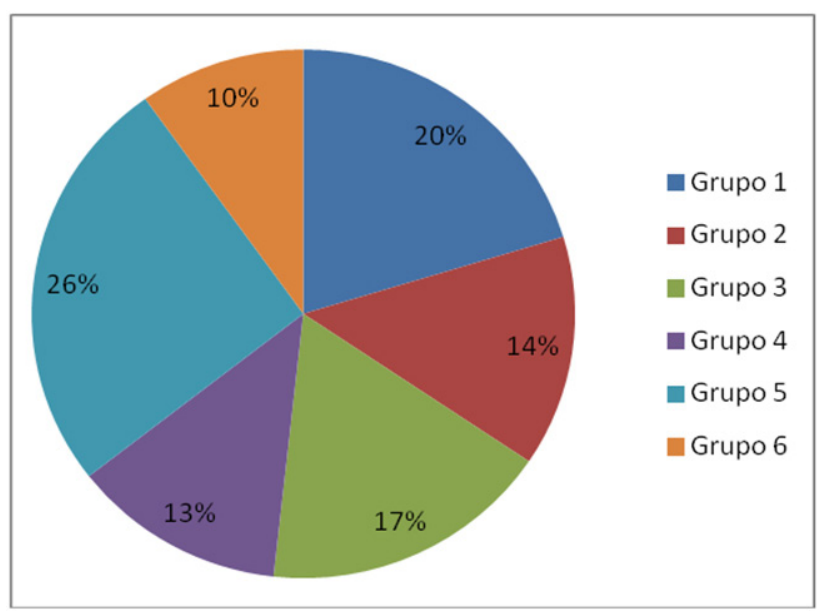

Fonte: elaboração própria

Importante destacar que, dos 3063 equipamentos, quase $50 \%$ não possui todas as informações no Cadastro Nacional de Museus, o que evidencia escassez de informações de grande parte dos museus brasileirose que acaba dificultando estudos mais precisos na área de museus. E ainda de acordo com a Relação Anual de Informações Sociais, em 2010, apenas 460 museus possuem CNPJ. Logo, essas instituições têm a sua gestão dificultada, principalmente quanto à falta de orçamento próprio e quanto à atividade de captação de recursos (IBRAM, 2014).

Ao analisar a distribuição dos clusters por região, percebe-se a concentração do grupo 1 na região Nordeste, cerca de $50 \%$ dos museus, e do grupo 6 no Sudeste, pouco mais de $80 \%$ dos equipamentos. Os grupos 3 e 5 são formados predominantemente por museus das regiões Sudeste e Sul. Os da região Sul estão ausentes somente no sexto grupo (Gráfico 2).

\section{Gráfico 2 - Distribuição dos grupos por regiões (\%)}

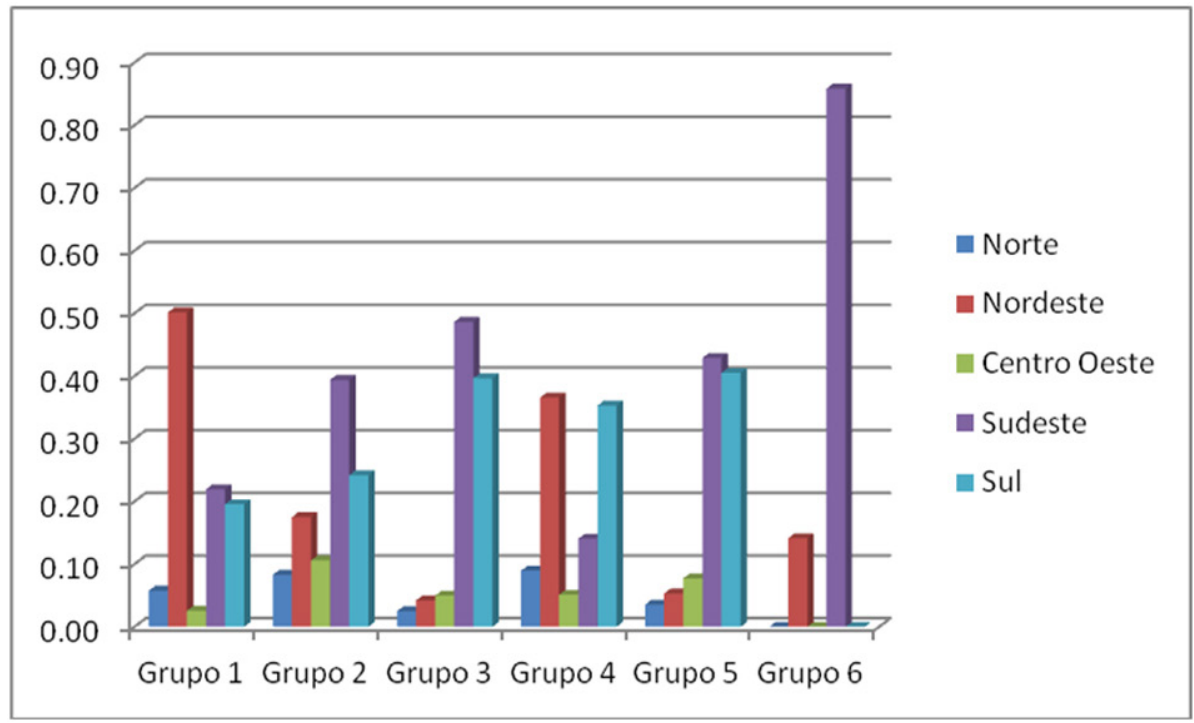


O grupo 1 apresenta uma distribuição bastante uniforme entre os estados brasileiros, embora com alguma concentração em alguns estados do Nordeste. Já no cluster 3 , o dos museus localizados nas regiões Sul e Sudeste, há maior evidência nos estados de São Paulo, Rio Grande do Sul,
Minas Gerais, Paraná e Santa Catarina (Tabela 1).

No grupo 6, museus dos estados de São Paulo e Rio de Janeiro somam $85 \%$ das instituições do agrupamento, os $15 \%$ restantes correspondem a museus do Ceará.

Tabela 1 - distribuição dos grupos por Unidades da Federação" (\%)

\begin{tabular}{lcccccc}
\hline \multicolumn{1}{c}{ Unidade } & Grupo & Grupo & Grupo & Grupo & Grupo & Grupo \\
\multicolumn{1}{c}{ Federativa } & 1 & 2 & 3 & 4 & 5 & 6 \\
\hline Rondônia & 0,00 & 0,01 & 0,01 & 0,00 & 0,00 & 0,00 \\
Acre & 0,01 & 0,00 & 0,01 & 0,00 & 0,01 & 0,00 \\
Amazonas & 0,01 & 0,00 & 0,00 & 0,09 & 0,00 & 0,00 \\
Roraima & 0,00 & 0,00 & 0,00 & 0,00 & 0,00 & 0,00 \\
Pará & 0,02 & 0,06 & 0,00 & 0,00 & 0,01 & 0,00 \\
Amapá & 0,00 & 0,00 & 0,00 & 0,00 & 0,01 & 0,00 \\
Tocantins & 0,01 & 0,01 & 0,00 & 0,00 & 0,01 & 0,00 \\
Maranhão & 0,01 & 0,00 & 0,00 & 0,05 & 0,00 & 0,00 \\
Piauí & 0,02 & 0,01 & 0,00 & 0,00 & 0,00 & 0,00 \\
Ceará & $0,0,07$ & 0,12 & 0,11 & 0,00 & 0,11 & 0,00
\end{tabular}




\begin{tabular}{lcccccc} 
Rio Grande do Sul & 0,11 & 0,08 & 0,15 & 0,18 & 0,20 & 0,00 \\
Mato Grosso do & & & & & & \\
Sul & 0,00 & 0,06 & 0,01 & 0,00 & 0,03 & 0,00 \\
Mato Grosso & 0,00 & 0,05 & 0,01 & 0,00 & 0,02 & 0,00 \\
Goiás & 0,02 & 0,00 & 0,02 & 0,05 & 0,03 & 0,00 \\
Total & 1,00 & 1,00 & 1,00 & 1,00 & 1,00 & 1,00 \\
\hline \hline
\end{tabular}

Fonte: elaboração própria

A variável natureza administrativa (tipo de gestão dos museus) foi igualmente significativa para a construção dos agrupamentos (veja Gráfico 3). Em todos os grupos, percebe-se uma concentração maior de museus de gestão pública em geral. No entanto, pouco mais de $50 \%$ dos museus do grupo 5 possuem gestão pública municipal, enquanto o grupo 6 , formado por museus de São Paulo, Rio de Janeiro e Ceará detém $36 \%$ de seus museus em administração privada (Gráfico 3).

\section{Gráfico 3 - distribuição dos grupos por gestão (\%)}

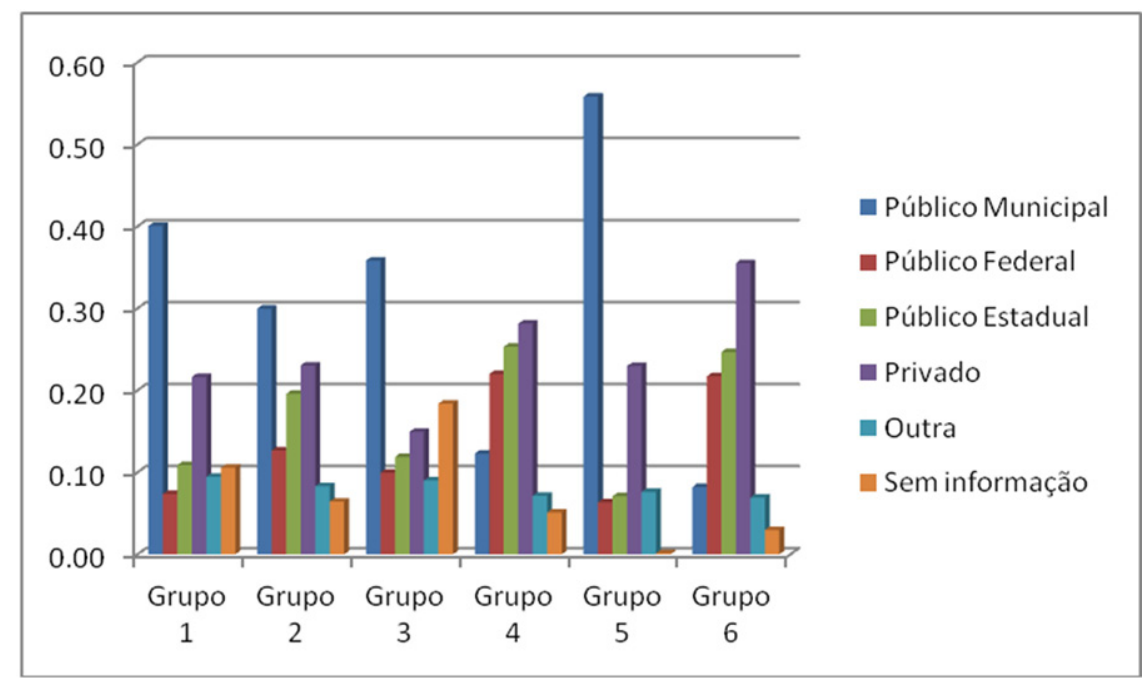

Fonte: elaboração própria

Com respeito à temática das coleções permanentes dos museus, a distribuição entre os grupos não se diferenciamuito, destacando-se museus da categoria "Documental e Histórico" e "Sem Informa- ção" (Gráfico 4). No entanto, o grupo 3 se diferencia desse padrão, sendo formado apenas por museus da categoria "Sem Informação", ou seja, que não possuíam informações sobre o acervo no CNM. 


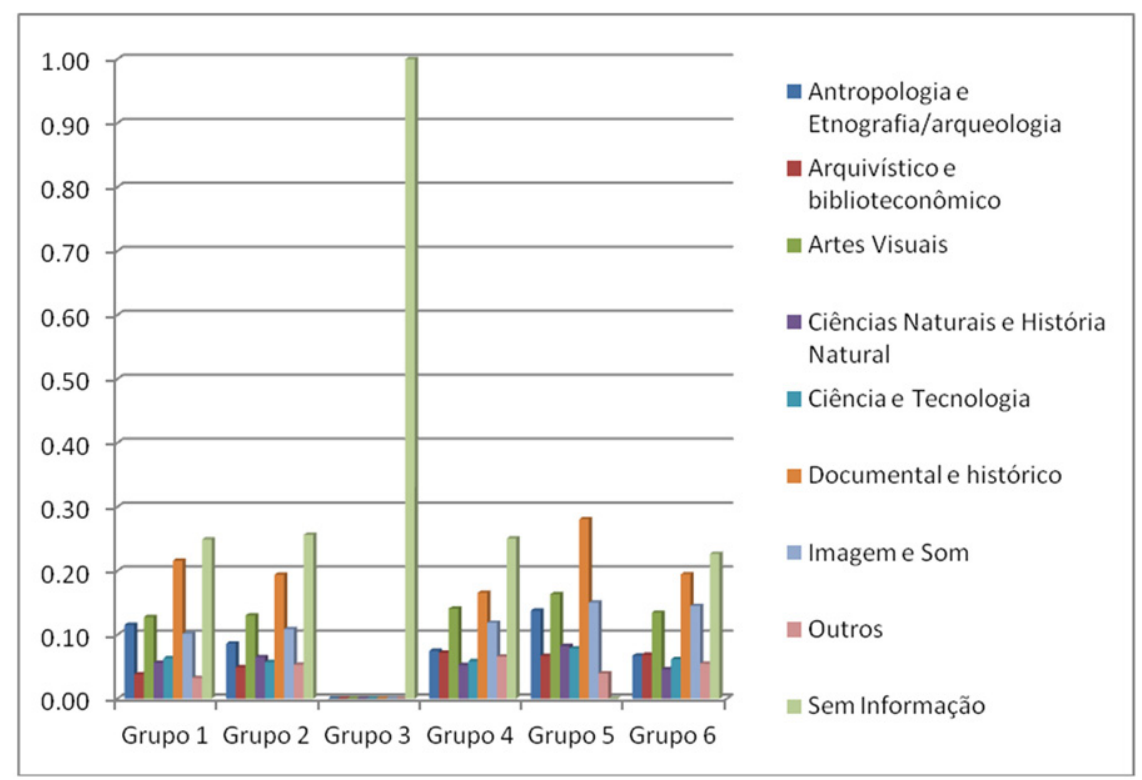

Fonte: elaboração própria

Observamos também que o tamanho das cidades é uma variável importante, medida pelo tamanho da população (Tabela 3). Os grupos 4 e 6 são formados basicamente por museus localizados em cidades grandes, predominantemente com mais de um milhão habitantes. $O$ grupo 1 é formado, em sua maioria, por museus localizados em municípios pequenos, com menos de 50 mil habitantes na região Nordeste.

O segundo grupo engloba os museus localizados em cidades médias das regiões Sudeste, Sul e Nordeste, municípios com 100 a 1 milhão de habitantes.

\section{Gráfico 5 - Distribuição dos clusters pelo tamanho dos municípios (\%)}

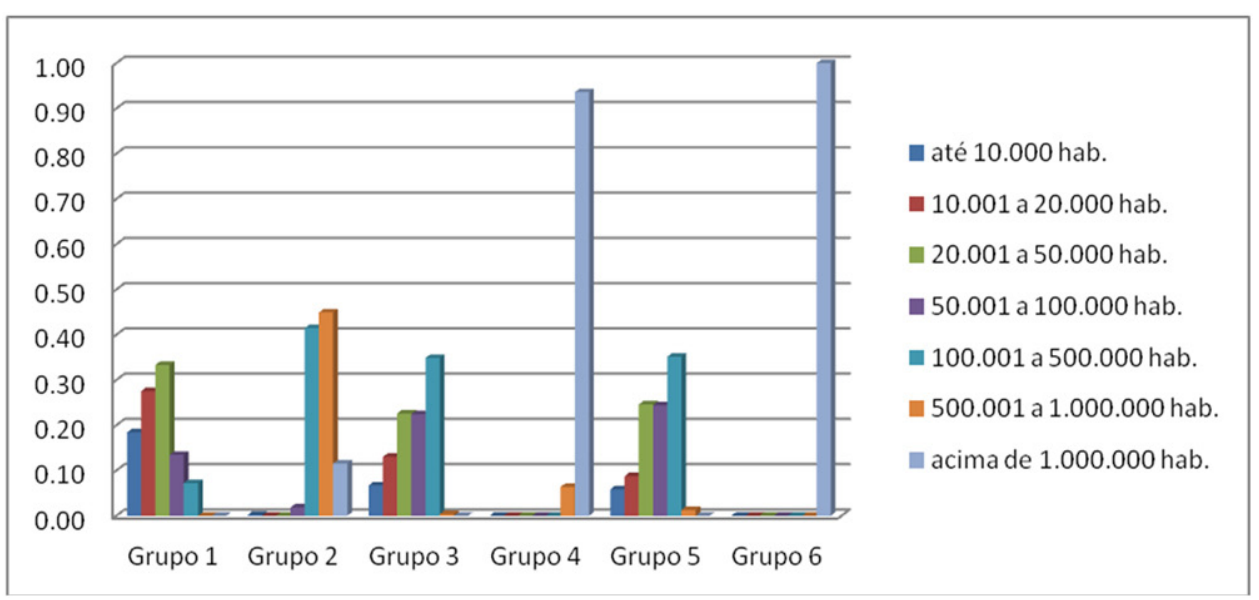

Fonte: elaboração própria 
A variável estrutura para turistas estrangeiros não foi muito relevante para a formação dos perfis, pois os museus brasileiros, em sua grande maioria, não apresentam esse tipo de estrutura (Gráfico 6), cerca de 90\%. No entanto, o grupo 6 dos estados de São Paulo e Rio de Janeiro, destacou-se pelo elevado percentual de museus que possuem tal estrutura (36\%).

\section{Gráfico 6 - Distribuição dos grupos por estrutura para turistas estrangeiros}

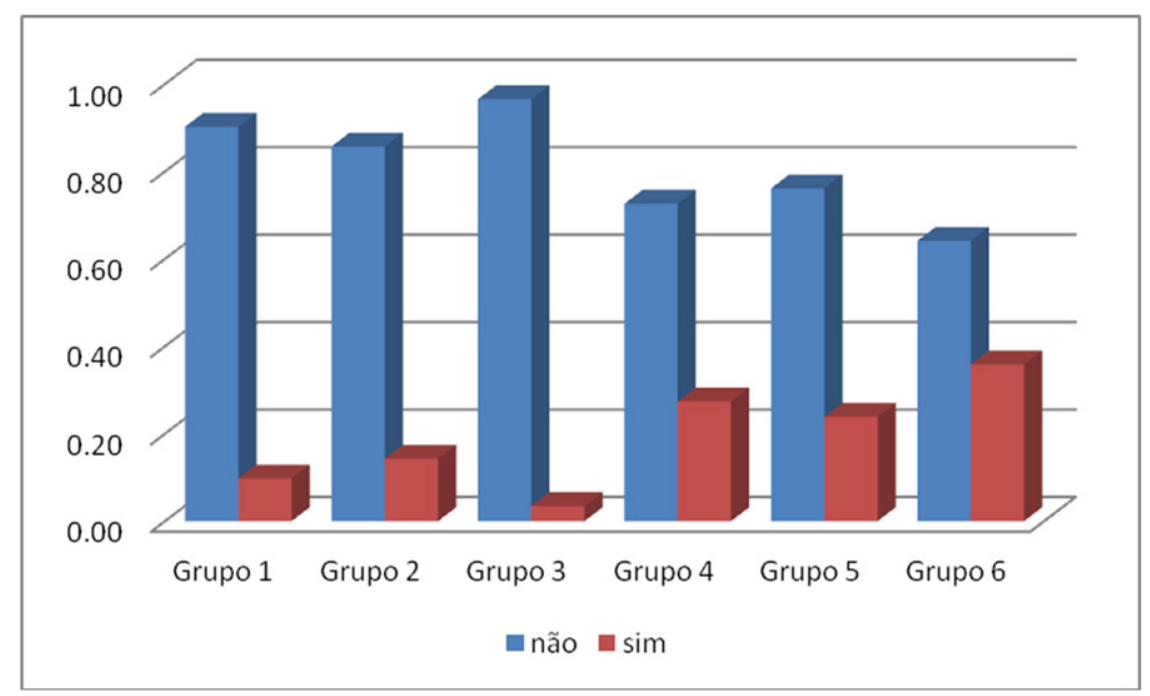

Fonte: elaboração própria

Outra característica importante dos museus brasileiros é a oferta de visitas guiadas. $O$ grupo 3 se destaca por grande parte de seus museus, cerca de $90 \%$, não ofere- cer esse tipo de visita, e já o grupo 5 se destaca por apresentar uma situação contrária a essa, cerca de $90 \%$ oferecerem visitas com acompanhamento de guias (Gráfico 7).

\section{Gráfico 7 - Distribuição dos grupos por visitadas guiadas}

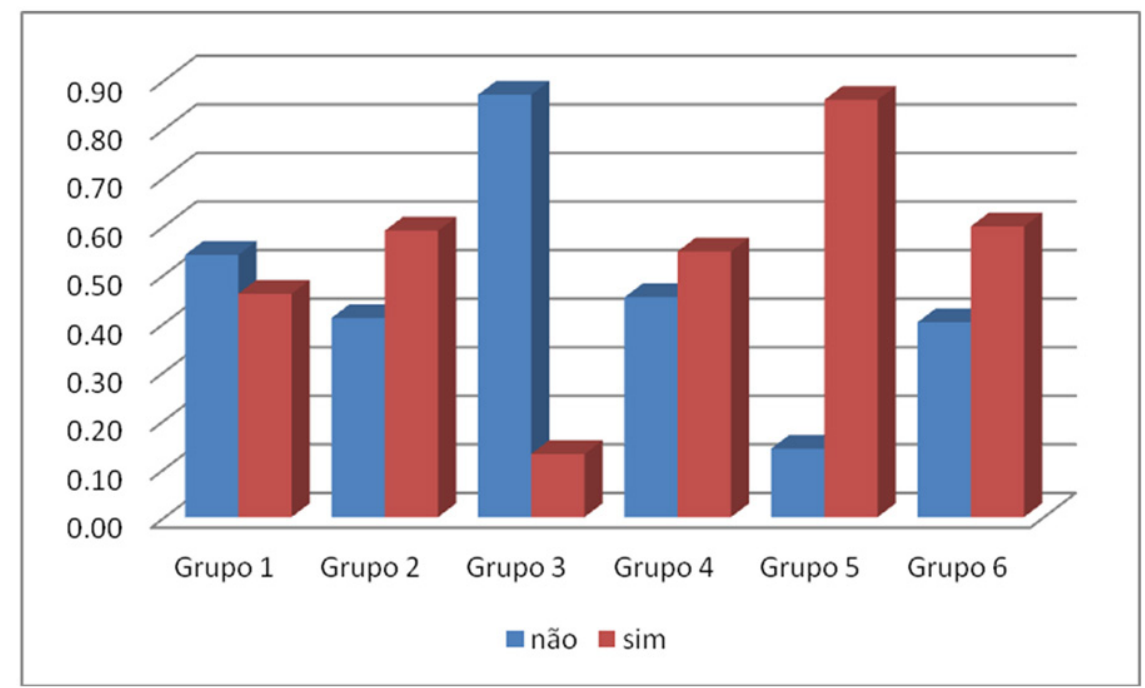

Fonte: elaboração própria 
Ainda a respeito das estruturas dos museus, analisamos a existência de bibliotecas e arquivos históricos nesses equipamentos. Cerca de $70 \%$ dos museus brasileiros não possuem bibliotecas e pouco mais de $65 \%$ não possuem arquivo histórico. No entanto, como mostram os gráficos 6 e 7 , dentre os museus que possuem tais instalações, mais de $70 \%$ permitem acesso ao público.

\section{Gráfico 8 - Distribuição dos grupos por acesso à biblioteca}

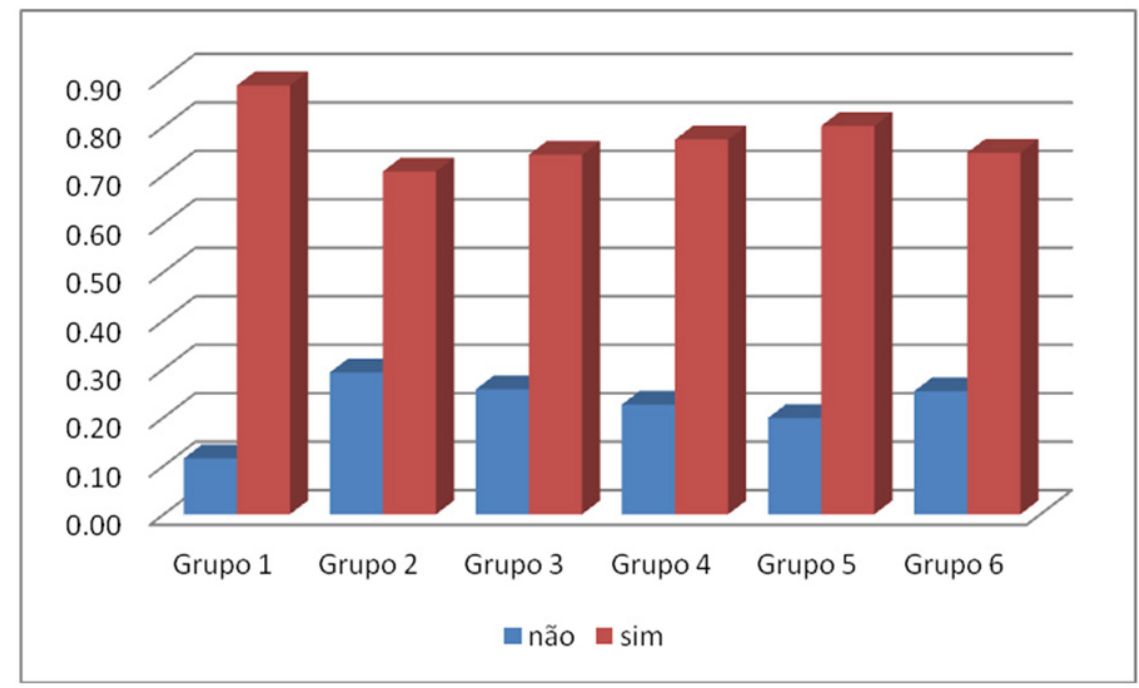

Fonte: elaboração própria

\section{Gráfico 9 - Distribuição dos grupos por acesso ao acervo histórico}

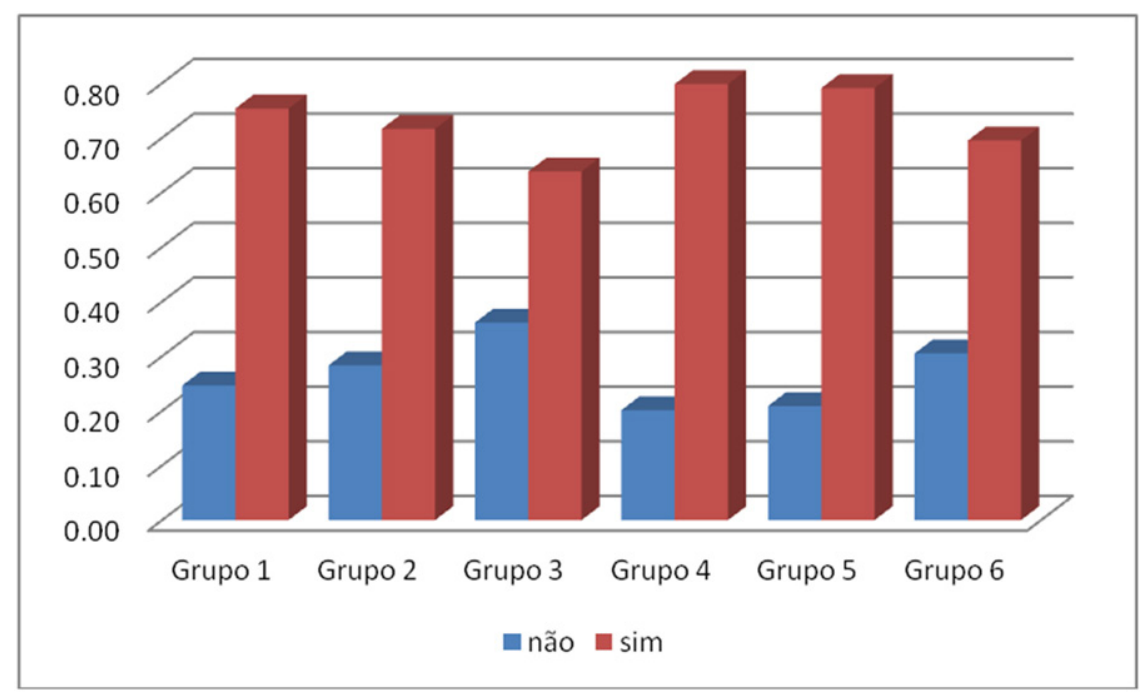

Fonte: elaboração própria 
Através dos indicadores socioeconômicos, o grupo 1, composto apenas por museus localizados em municípios com menos de 50 mil habitantes, detém o menor número de mortes por causas externas, além das menores proporções de adultos com ensino médio completo e de domicílios com acesso a esgotamento sanitário (tabela 2).

O grupo 2, instituições localizadas em municípios com mais de 100 mil habitantes, possui a maior despesa em cultura per capita, já o grupo 4 abrange os equipamentos localizados em municípios com a menor despesa em cultura per capita e a maior proporção da população com ensino médio completo.

Por sua vez, o grupo 6 é formado por museus em municípios com a maior renda média dos ocupados, pouco mais de $\mathrm{R} \$ 2.030$ per capita. Além da maior média de mortalidade e proporção de domicílios com acesso a esgotamento sanitário.

A despesa em cultura per capita em todos os grupos não apresentou valores muitos díspares, variando de $R \$ 34,80$ (Grupo 3) a R\$ 49,70 (Grupo 2).

\section{Tabela 2 - Variáveis socioeconômicas}

\begin{tabular}{|c|c|c|c|c|c|c|}
\hline Variável & $\begin{array}{c}\text { Grupo } \\
1\end{array}$ & $\begin{array}{c}\text { Grupo } \\
2\end{array}$ & $\begin{array}{c}\text { Grupo } \\
3\end{array}$ & $\begin{array}{c}\text { Grupo } \\
4\end{array}$ & $\begin{array}{c}\text { Grupo } \\
5\end{array}$ & $\begin{array}{c}\text { Grupo } \\
6\end{array}$ \\
\hline $\begin{array}{l}\text { Mortalidade (número } \\
\text { de mortes por causa } \\
\text { externa) }\end{array}$ & 35,0 & 548,8 & 90,0 & $1.871,9$ & 100,4 & $5.321,7$ \\
\hline $\begin{array}{c}\text { Proporção da } \\
\text { população com ensino } \\
\text { médio completo (\%) }\end{array}$ & 24,6 & 52,0 & 35,7 & 54,9 & 36,0 & 52,7 \\
\hline $\begin{array}{c}\text { Proporção de } \\
\text { domicílios com acesso } \\
\text { a esgotamento } \\
\text { sanitário (\%) }\end{array}$ & 31,6 & 68,9 & 62,7 & 75,3 & 59,1 & 91,7 \\
\hline $\begin{array}{c}\text { Despesa em cultura } \\
\text { per capita }(R \$)\end{array}$ & 44,0 & 49,7 & 34,9 & 34,8 & 41,2 & 42,8 \\
\hline $\begin{array}{l}\text { Renda dos ocupados } \\
\qquad(\mathrm{R} \$)\end{array}$ & 674,0 & $1.811,7$ & $1.225,8$ & $1.874,4$ & $1.248,3$ & $2.030,7$ \\
\hline
\end{tabular}

Fonte: elaboração própria 
Ao combinar essas descrições, podemos identificar tipos característicos dos museus brasileiros de acordo com as variáveis que selecionamos. Deste modo, as especificidades de cada um dos tipos são assim delineadas:

Tipo 1: museus de gestão municipal localizados em municípios com menos de 50 mil habitantes, principalmente na regiãoNordeste, e que apresentaram a menor mortalidade por causa externa, as menores proporções de adultos com ensino médio completo e de domicílios com acesso a esgotamento sanitário, além da menor renda média per capita.

Tipo 2: museus localizados em municípios das regiões Sudeste e Sul com população superior a 100 mil habitantes e que apresentaram a maior despesa média em cultura per capita.

Tipo 3: equipamentos, principalmente, de gestão municipal e sem informação sobre a gestão localizados em municípios do Sudeste e Sul com população entre 20 mil e 500 mil habitantes. Destaca-se, nesse grupo, o acervo da categoria "Sem Informação" e por não oferecer visitas guiadas.

Tipo 4: concentra museus de municípios das regiões Nordeste e Sul com população superior a um milhão, além da menor média em despesa em cultura per capita. Os equipamentos também se destacam pelas gestões privada e estadual.

Tipo 5: museus localizados em municípios das regiões Sudeste e Sul com população entre 20 mil e 500 mil habitantes, predominantemente com gestão municipal. Destaca-se, nesse grupo, por oferecem visitas guiadas.

Tipo 6: museus localizados em municípios dos estados de São Paulo e Rio de Janeiro e Ceará com uma população superior a um milhão de habitantes e que apresentam as maiores médias de renda dos ocupados e de domicílios com acesso a esgotamento sanitário. Os museus destacam-se por serem em sua maioria de gestão privada e apresentar o maior percentual de equipamentos com presença de estrutura para turistas estrangeiros.

\section{4 - Conclusões}

A aplicação de análise de aglomerados ao caso de museus brasileiros cadastrados pelo IBRAM, tendo por unidade de análise o município, mostrou que a distribuição no espaço guarda características específicas. A análise de aglomerados pode, portanto, contribuir para direcionar uma política, levando em conta as especificidades desses equipamentos. Conhecer os potenciais e fragilidades do setor museal no Brasil é de suma importância para a busca de instrumentos que possam fortalecer as potencialidades do mesmo.

A distribuição de museus é bastante concentrada na região Sudeste, corroborando o achado - segundo um estudo "II realizado pelo IBRAM - de que os equipamentos que tiveram mais sucesso em captar recursos públicos de incentivo fiscal, independentemente da natureza administrativa também se localizam no Sudeste, ou seja, também há concentração de beneficiários dos incentivos. Tais recursos são imprescindíveis para o funcionamento das instituições, uma vez que os custos fixos são elevados. Ademais, o tipo prevalecente é o de museus de gestão da esfera municipal, ratificando a importância da descentralização da gestão cultural como proposto pelo Sistema Nacional de Cultura. A municipalização da política cultural deve ser acompanhada pelo provimento de recursos que assegurem a sustentabilidade destes equipamentos. 
Sendo assim, uma política que incentive este equipamento como centralidade urbana deverá considerar tais especificidades. Em agenda de pesquisa futura, pretende-se selecionar alguns museus como emblemáticos dentro de cada um dos perfis e proceder a uma avaliação de impactos sobre o entorno.

\section{Bibliografia:}

BEDATE, A. M.; HERRERO, L. C.; SANZ, J. A. Economic valuation of a contemporary art museum: correction of hypothetical bias using a certainty question. Journal of Cultural Economics, 33(3), pp. 185-199, 2009.

BILLE, T.; SCHULZE, G. G. Culture in urban and regional development. In: GINSBURGH, Victor A.; THROSBY, David (Eds.). Handbook of the Economics of Art and Culture. Oxford: North-Holland Elsevier, 2008.

CWI, D. Public support of the arts: three arguments examined. Journal of Cultural Economics, 4(2), pp. 39-62, 1980.

DINIZ, S. C.; MACHADO, A. F. Analysis of the Consumption of Artistic-Cultural Goods and Services in Brazil. Journal of Cultural Economics, v. 35, pp. 1-18, 2011.

FARIA, D.; MACHADO, A. F. Factors associated to art museum visitation: the Inhotim case. Business Management Review (BMR), v. 5, pp. 196-207, 2015.

FREY, B; MEIER, S. The economics of museums. In: GINSBURGH, Victor.; THROSBY, David (Eds.). Handbook of the Economics of Art and Culture. Oxford: North-Holland Elsevier, 2008.

IBRAM. Museus e a dimensão econômica: da cadeia produtiva à gestão sustentável. Brasília, 2014.

MINGOTI, S. A. Análise de dados através de estatística multivariada. Belo Horizonte: UFMG, 2007.

PASTERNAK, S.; BÓGUS, L. A distribuição dos equipamentos culturais numa cidade segregada: São Paulo. In: XII Seminário da Rede Iberoameri- cana sobre Globalização e Território em Belo Horizonte, 2012.

SANZ, J. A. L.; HERRERO, L. C. P. Valoración de bienes públicos relativos al patrimonio cultural. Aplicación comparada de métodos de estimación y análisis de segmentación de demanda. Hacienda Pública Española, nº 178, 2006.

Recebido em 10/01/2016

Aprovado em 08/02/2016
I Ana Flávia Machado. Nayara Souza Larissa Machado. Universidade Federal de Minas Gerais.

II Os museus localizados no Distrito Federal não foram incorporados na análise devido à falta de dados de despesa em cultura per capita.

III Museus e a dimensão econômica: da cadeia produtiva à gestão sustentável / Instituto Brasileiro de Museus Brasília, DF: IBRAM, 2014. (Coleção Museu, Economia e Sustentabilidade, 2) 